\title{
Dental education in Iraq: issues, challenges and future
}

\author{
Mohammad Hossein Khoshnevisan, 1,2 Ammar N.H. Albujeer, 3,4,5 Abbas Taher, ${ }^{5}$ Alya Almahafdha ${ }^{5,6}$
}

\author{
'Preventive Dentistry Research Center, Research Institute of Dental Sciences, Shahid Beheshti University of Medical Sciences, Tehran, Iran. \\ ${ }^{2}$ Community Oral Health Department, School of Dentistry, Shahid Beheshti University of Medical Sciences, Tehran, Iran. \\ ${ }^{3}$ Department of Stomatology, School of Medicine and Dentistry, Santiago de Compostela University, Santiago de Compostela, Spain. \\ ${ }^{4}$ School of Dentistry, Tehran University of Medical Sciences, Tehran, Iran. \\ ${ }^{5}$ Nab'a Al-Hayat Foundation for Medical Sciences and Health Care, Najaf, Iraq. \\ ${ }^{6}$ School of Medicine, International Campus, Tehran University of Medical Sciences, Tehran, Iran. \\ Correspondence to Ammar N. H. Albujeer (email: ammar.dent@yahoo.com) \\ (Submitted: 15 May 2017 - Revised version received: 28 May 2017 - Accepted: 05 June 2017 - Published online: 26 September 2017)
}

\begin{abstract}
Objective Medical sciences are the substance for appreciation of prevention and treatment of human diseases and improvement of one's quality of life. Dentistry on the other hand, is a highly demanding profession that requires standard and evidence-based training, so that upon graduation, dentists would be well prepared and qualified for challenging career. Therefore, using a dental curriculum with updated clinical and scientific foundation can help meeting the above objectives and many other requirements. Likewise, a dental curriculum is required to develop and improve skills, maintain comprehensive professional standards to provide more effective and efficient services to individuals and communities.

Given that the dental education can have a direct effect on oral health as well as overall health status at the national level, the aim of this paper was to review the current status of dental education system in Iraq. There are thirty dental faculties in Iraq currently. However, the oral health situation is in need of major improvement. This recognizes the importance of dental education reevaluation starting from curriculum structure, content, learning and assessment methods as well as administration and governance of dental education. There is a need for urgent attention in order to enable effective contribution of new dental graduates in improvement contribute in improvement and promotion of oral health for all citizens living in all communities at the national level.

Keywords dental curriculum, dental education system, oral health promotion, dmft index, Iraq
\end{abstract}

\section{Introduction}

Geographically, Iraq is located in strategically important area with multicultural population and abundant natural resources. Historically, the Iraqi civilization goes back to 7000 years ago. Sumerians' contribution to the field of education is well acknowledged. They had a great knowledge of medicine and other fields. They are also the ones who divided the circle into 360 degrees for the first time. Back in nineteenth century, when modern education started, a few available faculties were used exclusively by small wealthy families. At the time, religious faculties as the principal centers, provided elementary and religious education to majority of children nationwide.

It was not until 1970s that free compulsory education was established at all levels from primary to higher education. Among others, Baghdad and Najaf were the two cities that were famous for having the outstanding scientific and religious centers of the time for several decades. The number of very famous physicians and scientists are attributed to universities in this country. However, numerous political unrests have disturbed the progress and advancement of science in this country. The first dental school started in 1953 as part of medical University in Baghdad which was comparable with modern dental faculties of the time. ${ }^{2}$ Subsequently, four other faculties were established as reported in Table 1 . The dental education was initially a 5-year program, using British curriculum. Aside from local graduates, there are some foreign-trained dentists who are practicing dentistry in Iraq as well. ${ }^{2}$

Similar to some dental programs around the world, the training of dental students is mainly focused on Treatment instead of Prevention in Iraq. ${ }^{3}$ This policy has resulted in oral health deterioration of Iraqi population as expected. It seems that global standardization of dental education is inevitable for further improvement of oral health in Iraq.

\section{Dental Education System}

By 2003, there were four dental faculties at the national level, with two of them had limited postgraduate programs. Currently, there are 36 dental faculties (Table 2), 16 public and 20 private, offering a 5-year program with B.D.S degree. The number of dental students in Iraq is incredibly rising due to increasing number of admissions each year, especially by private dental faculties. It should also be noted that the number of Iraqis studying dentistry abroad is increasing as well. There is an urgent need for the three Ministries of Health, Higher Education, and Ministry of Planning to re-address the total number of admissions for public and private faculties of dentistry as soon as possible.

After admission, students take the basic medical and dental science courses during the first 2 years, and then focus on didactic and clinical dentistry preclinical training for the last 3 years. Although, dental curriculum has been revised many times since 1953 to 2016, and revisions followed the new educational methodologies, such as evidence-based approaches, problem-based learning and case presentations through comprehensive patient treatment. However, the skills and competencies of new dental graduates are not translated into daily preventive practice yet.

\section{Dental Education Program}

The curriculum for B.D.S. program in Iraq has 46 subjects to be taken in 5 years. The teaching language is English, and subjects are taken in two stages as shown in Table 3. 
In stage I (first and second year), students have to complete applied and non-applied medical and dental basic sciences, passing 16 subjects. The courses for these 2 years include: medical physics (4 units), medical chemistry (4 units), medical biology (4 units), dental anatomy (3 units), computer (4 units), human rights ( 2 units), Arabic literature language ( 2 units), Embryology (3 units), dental materials (3 units), prosthodontics (5 units), oral histology (3 units), general histology (4 units), general anatomy (4 units), physiology (4 units) and biochemistry (4 units). The total hours of stage I are 750 hours for theory and 840 hours for practical training (demonstration and laboratory work). After successful completion and passing of these subjects, students will enter the second stage of the training program. In year 3-5 students, they take preclinical and clinical courses. The preclinical and clinical part in the stage II has 118 units for the following subjects: prosthodontics (14 units), preclinical fixed prosthodontics and operative dentistry ( 8 units), oral surgery (13 units), community dentistry (3 units), pharmacology (4 units), general pathology (4 units), dental radiology (3 units), microbiology (4 units), Infection control (1 unit), operative/ endodontics (8 units), periodontology (10 units), orthodontics (9 units), oral pathology (5 units), general medicine (4 units), general surgery ( 3 units), pedodontics ( 5 unit), clinical endodontics, clinical fixed prosthodontics (7 units), oral medicine (3 units), preventive dentistry (4 units), dental implantology (1 unit), forensic dentistry (1 unit), dental occlusion (1 unit) and research project (4 units).

The total hours for stage II is 4410 hours, with 1140 hours for lectures (Theory) and 3270 hours for practical training. ${ }^{4}$ In addition, there are obligatory summer courses, which are about $20 \%$ of the total program score.

In summary, students shall successfully complete and pass a total of 171 units in 5-year program as shown in Table 3.

Since 2016, the Ministry of Higher Education and Scientific Research added national exam under the name of "Quality Accreditation Exam" for all graduated dental students take place after finishing the 5-year dental program. This is the mechanism that the government approved the quality of dental education for new graduates both in public and private institutions in the country.

After passing the national exam, dental graduates will be eligible for the title of B.D.S, but should still fulfill 2 years of obligatory Practice in rural primary health care centers and 1 year in hospital spatiality dental clinic in cities, before being

\begin{tabular}{lcc}
\hline Table 1. Profile of Iraqi dental colleges & & \\
\hline Dental schools information & $\mathbf{2 0 0 3}$ & $\mathbf{2 0 1 6}$ \\
\hline Dental colleges & 4 & 30 \\
Dental students (undergraduate) & 1,000 & 13,000 \\
Dental students (postgraduate) & 10 & 150 \\
Total admission/year (undergraduate and & 200 & 2,760 \\
postgraduate) & & \\
Graduates/year & 250 & $1,000-1,500$ \\
Postgraduate programs & 10 & $10-11$ \\
Postgraduate disciplines & 5 & $10-11$ \\
Academic staff & 50 & 350 \\
Schools for laboratory technicians & 1 & 3 \\
Schools for hygienists & 0 & 0 \\
\hline
\end{tabular}

able to obtain the license from the Ministry of Health to practice dentistry in a private clinic.

\section{Oral Health Status}

The Iraqi health care delivery system is largely hospital-based and capital-intensive model with less emphasis on prevention. Public dental services are mainly provided by the Ministry of Health $(\mathrm{MOH})$ rather than the dental faculties' affiliated hospitals that are operated by the Ministry of Higher Education.

\begin{tabular}{|c|c|c|}
\hline No. & University name & Founded \\
\hline 1 & University of Baghdad & 1953 \\
\hline 2 & University of Al Mosul & 1982 \\
\hline 3 & Al-Mustansiriya University & 2000 \\
\hline 4 & Babylon University & 2002 \\
\hline 5 & University of Tikrit & 2004 \\
\hline 6 & Basrah University & 2005 \\
\hline 7 & University of Kufa & 2006 \\
\hline 8 & Al- Yarmouk University College & 2006 \\
\hline 9 & Ibn Hayyan University College & 2009 \\
\hline 10 & Al Rafidain University College & 2009 \\
\hline 11 & University of Anbar & 2010 \\
\hline 12 & University of Karbala & 2011 \\
\hline 13 & Al-Kafeel University College & 2011 \\
\hline 14 & University of Wasit & 2012 \\
\hline 15 & University of Maysan & 2012 \\
\hline 16 & University of Qadisiyah & 2013 \\
\hline 17 & University of Iraq & 2013 \\
\hline 18 & University of Muthanna & 2013 \\
\hline 19 & Al-Israa University College & 2013 \\
\hline 20 & Dejlah University College & 2013 \\
\hline 21 & Al-Hussein University College & 2013 \\
\hline 22 & Asul-dien University College & 2013 \\
\hline 23 & University of Kirkuk & 2014 \\
\hline 24 & Al-Rashid University College & 2014 \\
\hline 25 & $\begin{array}{l}\text { National University of Science and } \\
\text { Technology College }\end{array}$ & 2015 \\
\hline 26 & Uruk University College & 2015 \\
\hline 27 & University of Dhi Qar & 2016 \\
\hline 28 & Al-Safwah university College & 2016 \\
\hline 29 & Al-Kitab University College & 2016 \\
\hline 30 & Al-Hilla University College & 2017 \\
\hline 31 & Belad Al-Rafdein University College & Under construction \\
\hline 32 & Qurtuba University College & Under construction \\
\hline 33 & $\begin{array}{l}\text { Al-Mustafa Al-Amen University } \\
\text { College }\end{array}$ & Under construction \\
\hline 34 & Al-Bayyan University College & Under construction \\
\hline 35 & Al-Mustaqbal University College & Under construction \\
\hline 36 & Al-Ammed University College & Under construction \\
\hline
\end{tabular}


In addition, the private sector is actively providing dental services to the general population. The private sector is supervised and regulated by the $\mathrm{MOH}$ as well. Although, the $\mathrm{MOH}$ provides curative and prevention care, the private sector is mainly focused on emergency and curative services.

In addition to oral health status, aside from a few sporadic small surveys, there are two major national surveys of children conducted by the Iraqi Ministry of Health over 2001 and 2012 The first survey was conducted in Baghdad, Ninevah and Basrah provinces using 2040 samples of 15 -year-old children. The last survey was conducted in five provinces (Baghdad, Erbil, Najaf, Salahdien and Maysan) in 2012 using 3260 samples of 12-year-old children.

The 2001 national survey of 15 -year-old children in the three provinces demonstrated a DMFT index of 1.35 in the 2040 participating students. The 2012 national survey was conducted by the Iraqi $\mathrm{MOH}$ in collaboration with the WHO and using the WHO recommended Oral Health Assessment Form (1997) for clinical assessment of 12-year-old children in five provinces. The DMFT index for the 3260 participating students was 1.57 as shown in Figure 1.

\section{Oral Health Manpower}

Before 2003, the estimated number of registered dentists was less than 4000 according to Iraqi Dental Association records. In 2010, there were 4863 dentists with population ratio of

\begin{tabular}{cl}
\hline Table 3. & Dental colleges' curriculum in Iraq \\
\hline Stage 1 & \\
Year 1 & Applied and non-applied medical basic sciences. \\
Year 2 & $\begin{array}{l}\text { Applied medical basic sciences and preclinical dental } \\
\text { technique courses }\end{array}$ \\
Stage 2 & \\
Year 3 & Preclinical dental technique courses and medical sciences \\
Year 4 & $\begin{array}{l}\text { Completion of preclinical dental courses and start of clin- } \\
\text { ical courses - with obligatory summer preclinical training } \\
\text { courses. }\end{array}$ \\
Year 5 & $\begin{array}{l}\text { Clinical dental course (practical \& theory) - with obligatory } \\
\text { summer clinical training courses. }\end{array}$ \\
\hline
\end{tabular}

Table 4. Number of academic staff members in various departments of Iraqi dental colleges

\begin{tabular}{lc}
\hline Department & Staff numbers \\
\hline Oral and maxillofacial surgery & 60 \\
Oral and maxillofacial pathology & 10 \\
Oral and maxillofacial radiology & 10 \\
Oral medicine and diagnosis & 10 \\
Pediatric dentistry & 30 \\
Restorative and aesthetic dentistry & 70 \\
Periodontics & 20 \\
Prosthodontics (removable \& fixed) & 70 \\
Orthodontics & 40 \\
Endodontics & 30 \\
Total academic staff members in dental colleges & 350 \\
\hline
\end{tabular}

$1.7 / 10,000 .{ }^{6}$ In 2015 , there were 7277 dentists with population ratio of $2.3 / 10,000 .^{7}$ Currently, there are close to 8500 registered dentists, with dentist population ratio of 2.6 dentists for every 10,000 citizens. This number is growing rapidly with increasing number of dental graduates. A new objective is to achieve a new dentist population ratio of $6.4 / 10,000$ by 2020.

Most of these dentists working in public sector in the morning and private clinics in afternoon, no more than $10 \%$ of them are working as a university staff as demonstrated in Table 4 . The number of dental technician is required to increase in order to better serve the dentists and the public.

\section{Discussion}

Several decades of sanction and war have completely disrupted the socio-political and economic structure in Iraq, hampering progress in educational and scientific developments. As a result, most of the educational institutions including dental faculties require overall rehabilitation, including physical facilities, curriculum and dental education administration and governance as part of post-conflict reconstruction to name a few.

The scarce public resources for oral health in Iraq can never be sufficient to cover the cost of treatment for oral and dental diseases. ${ }^{7}$ Therefore, the oral health needs of the Iraqi population should be reflected in its dental curriculum. Preventive dentistry should be a major focus of dental education. With the hopes that, through competent teaching and learning methods, graduating dentists would have acquired the necessary skills and competencies that can enable them to contribute to oral health improvement of the population at the national level. Such curriculum should at the same time allow for student reflection, creativity and scientific inquiry. Yet any dental curriculum must be reviewed and updated regularly. Aside from learning science, and developing clinical skills, a dental graduate must learn ethics and the skills to become critical lifelong learner through continuing education and professional development. Also, we must appreciate that education in general, is tremendously vital for social change. However, if the oral health status in Iraq is not acceptable, there is a need for changing dental education system to benefit all citizens.

Faculty development is also very important. The way instructors teach dental students, has a profound effect on the direction of the profession in the future. The faculty can carefully evaluate and consider what role is expected of the

\section{DMFT 2012}

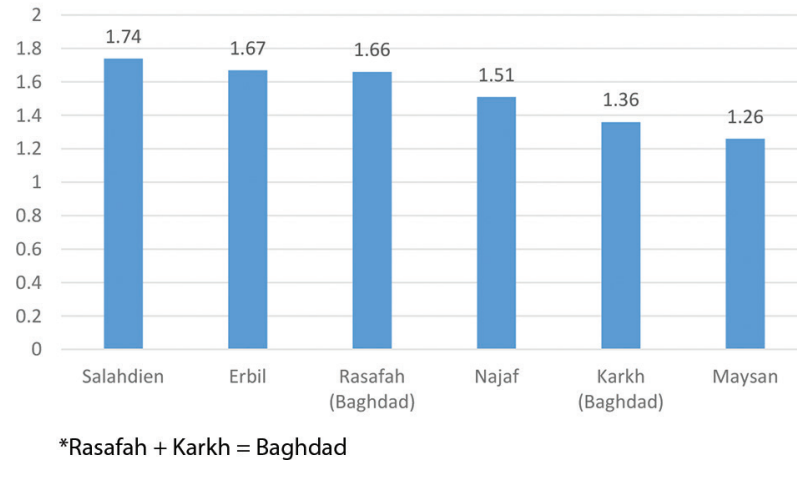

Fig.1 DMFT Index for 12-years-old children $(n=3260)$. 
dental professional to play in the community for both short and long term needs. We need to decide whether we want to "train" or "educate" our dental students in Iraq? By training, we teach our students to do a list of things, the same way as others did in the past, while by educating we teach our students to think critically and independently, to do things when justified and question or refer when indicated. By education we can develop innovative dental graduates who are insightful, thoughtful and not simply a passive consumer. These dental professionals are the real agents for social and scientific change.

On the other hand, a clear strategy should be made available for the number of dental faculties needed for Iraq. Given the current economic constraints of the country, establishment of any new standards in dental faculties requires enormous amounts of money as well as significant annual budgets to keep the faculties running. In absence of clear strategy, dental education would not be cost-effective; whether the capital is invested by public or private parties. Even the quality of dental education is especially vulnerable and will likely deteriorate in the face of annual budget shortages in existing faculties.

\section{Conclusion and Recommendation}

In conclusion, dental education in Iraq face many challenges. There are many approaches to meet these challenges, it is necessary to consider the local needs of the country, develop new strategies and define new governance for dental education to deal with acute problems and pave the way for educating a dentist with global standards for further improvement in oral health of the Iraqi population at the national level.

The dental education expanded considerably after 2003 in Iraq, in spite of all challenges and shortcomings that occurred after 2003. The number of dental faculties increased by almost nine folds (from 4 to 36 ) with increased number of dental student enrollment by six folds (from 250 to 1500) annually, without marked changes in postgraduate programs and positions. In relation to dental technician faculties, the expansion does not match with the increasing number of new dental faculties. Likewise, for the dental hygienist and dental nurses (assistants), there is extreme shortage of both, and there is a great need to incorporate these allied dental trainings to the existing dental faculties. Dental hygienists can play extremely important role in oral disease prevention and oral health promotion at the local, national and international levels. In this regard, the global goals of oral health 2020 strategy can be used as a guide for national policy development. ${ }^{9}$

\section{Acknowledgement}

The authors are thankful to Dr. Ibtisam Aboud, the former director of oral health center in the Iraqi Ministry of Health for her assistance in providing the DMFT data for this article.

\section{Conflict of Interest}

None.

\section{References}

1. Ranjan RK, Jain PC. The decline of the educational system in Iraq. J Peace Stud. 2009;16(1-2).

2. University of Baghdad CoD. History of College of Dentistry 2017 [Available from: http://www.codental.uobaghdad.edu.iq/PageViewer. aspx?id=2.

3. Albujeer AN, Taher A. Dental education and oral health service in Iraq. Iranian J Pub Health. 2017;46:713-714.

4. Research MoHEaS. College of Dentistry Curriculum. 2016.

5. Research MoHEaS. University of Baghdad, College of Dentistry, Curriculum. Unpublished. 2016.

6. Health Mo. Annual Statistical Report 2010. 292.

7. Health Mo. Annual Statistical Report 2015. 2015.

8. Allawi J. Allocating Resources in Health Care Services. Journal of Contemporary Medical Sciences. 2017;3:237-238.

9 Hobdell M, Petersen PE, Clarkson J, Johnson N. Global goals for oral health 2020. International dental journal. 2003;53(5):285-258.

This work is licensed under a Creative Commons Attribution-NonCommercial 3.0 Unported License which allows users to read, copy, distribute and make derivative works for non-commercial purposes from the material, as long as the author of the original work is cited properly. 